\title{
Endogenous energy production by mature boar spermatozoa
}

\author{
A. R. Jones and D. Milmlow \\ Department of Biochemistry, The University of Sydney, Sydney NSW 2006, Australia
}

\begin{abstract}
When incubated in the absence of exogenous substrates, washed boar spermatozoa maintained a high energy charge potential (ECP) for at least $5 \mathrm{~h}$. Addition of 3-chloro1-hydroxypropanone, an inhibitor of triosephosphate isomerase and glyceraldehyde 3-phosphate dehydrogenase, at any time caused the ECP to decline and fructose-1,6bisphosphate, dihydroxyacetone phosphate and glycerol to accumulate. There appear to be two endogenous substrates that are degraded ultimately to produce the triosephosphates which allow the cells to produce lactate for the mitochondrial synthesis of ATP. One substrate generates minor amounts of glycerol 3-phosphate whereas the other substrate degrades to glycerol and may be di-glycerides, or tri-glycerides, or both.
\end{abstract}

\section{Introduction}

ATP is necessary for many purposes within spermatozoa, such as the maintenance of the intracellular milieu by the active extrusion of ions and modifications to the structure and function of the cell during maturation, capacitation and fertilization, but the process of motility accounts for most of the ATP that is consumed by mature spermatozoa (Bohnensack and Halangk, 1986; Ford and Rees, 1990; Mita et al., 1991; Hofmann ef al., 1992). Although there are marked species differences in the manner by which spermatozoa generate ATP, boar spermatozoa are restricted to fructose, glucose, glycerol, glycerol 3-phosphate and lactate as metabolic substrates and, in this species at least, spermatozoa are totally reliant on the glycolytic pathway for the ultimate production of acetyl CoA for the mitochondrial generation of ATP (Jones and Chantrill, 1989).

Once in the female reproductive tract, spermatozoa must maintain their motility and for this it is generally assumed that substrates for ATP generation are obtained from tract secretions. While this may be so, Tash and Mann (1973) observed that thrice-washed ram spermatozoa had poor motility and produced low concentrations of cyclic AMP when incubated under anaerobic conditions for $1 \mathrm{~h}$, whereas a further hour under aerobic conditions with no added substrate resulted in good motility and high concentrations of cyclic AMP. Similarly, when washed ram spermatozoa were incubated for $5 \mathrm{~h}$ at $16^{\circ} \mathrm{C}$ with no exogenous substrate, they maintained high concentrations of cyclic AMP and had good motility. Mann and Lutwak-Mann (1981) later commented that "In the total absence of either seminal plasma or extraneous metabolizable substrate, spermatozoa retain their motility provided oxygen is available; owing to endogenous respiration they continue to take up oxygen, albeit for a shorter period than in whole semen." Washed mature spermatozoa from rhesus monkey ejaculates, when incubated in a substrate-free medium, were completely immotile at the end of a $1.5 \mathrm{~h}$ anaerobic period but

Received 2 May 1997. motility was restored to almost normal values by aeration (Hoskins and Patterson, 1968).

While examining the effects of chemical inhibitors on the metabolic activity of washed boar spermatozoa (Jones and Porter, 1995), we observed that these cells could maintain high concentrations of ATP for prolonged periods in vitro when incubated under aerobic conditions in the absence of exogenous substrates. The results of our investigations into this phenomenon, by the judicious use of specific metabolic inhibitors, are presented here.

\section{Materials and Methods}

\section{Chemicals and substrates}

L- $\alpha$-Glycerophosphorylcholine cadmium chloride complex grade 1 , bovine serum albumin (BSA) and D,L-glyceraldehyde were obtained from Sigma (St Louis, MO) and D,L-carnitine chloride from Merck (Darmstadt). 3-Chloro-1-hydroxy. propanone (CHOP) was prepared from 3-chloro-1-hydroxypropanone dimethyl acetal by the procedure of Jones et al. (1986). Neutralized solutions of CHOP $\left(10 \mathrm{mmol} \mathrm{l}^{-1}\right)$ were prepared immediately before use and added to incubations at a final concentration of $0.5 \mathrm{mmol} \mathrm{l}^{-1}$. 3-Bromopyruvate hydrate, supplied by Aldrich Chemical Co. (Milwaukee, WI), was recrystallized several times from dry chloroform, m.pt $54.7^{\circ} \mathrm{C}$. Aqueous solutions were neutralized with solid $\mathrm{NaHCO}_{3}$ and added to incubations as sodium bromopyruvate (BPA) at a final concentration of $0.5 \mathrm{mmol} \mathrm{1}^{-1} \cdot(R, S)-\alpha-$ bromohydrin phosphate biscyclohexylamine salt was prepared to established purity by the method of Jones and Gillan (1996a), 1,6-dichloro-1,6-dideoxy-D-fructose according to Jones and Morin (1995) and (R,S)-3-chlorolactaldehyde by the method of Williams et al. (1960). Etomoxir (sodium 2-[6-(4chlorophenoxy)-hexyl]-oxirane-2-carboxylate) was a gift from G. J. Cooney (Department of Endocrinology, University of Sydney) and penicillin G (Calbiochem, La Jolla, CA), ampicillin (Alphapharm, Glebe NSW) and tetracycline (Boehringer 
Mannheim Australia, Castle Hill, NSW) were purchased from the manufacturers. All enzymes and substrates were supplied by Boehringer Mannheim Australia and compounds were prepared as aqueous solutions and used at concentrations indicated in the text. All other chemicals and reagents were of analytical grade and all solutions were prepared in water purified by reverse osmosis.

\section{Collection and preparation of spermatozoa}

Cauda epididymides, removed from the testis-epididymis complex of mature boars (Sus scrofa: various crosses of Duroc, Hampshire, Landrace and Large White) 15-20 min after slaughter at the abattoir, were immediately placed in Dewar flasks containing phosphate-buffered saline (PBS) at $34^{\circ} \mathrm{C}$. (PBS consisted of $\mathrm{NaCl}\left(139 \mathrm{mmol} \mathrm{I}{ }^{-1}\right), \mathrm{KCl}\left(4.7 \mathrm{mmol} \mathrm{I^{-1 }}\right)$, $\mathrm{MgSO}_{4}\left(1.2 \mathrm{mmol} \mathrm{l}^{-1}\right), \mathrm{Na}_{2} \mathrm{HPO}_{4}\left(3.1 \mathrm{mmol} \mathrm{l}{ }^{-1}\right), \mathrm{NaH}_{2} \mathrm{PO}_{4}$ $\left(0.8 \mathrm{mmol} \mathrm{l}^{-\mathrm{I}}\right)$ and $\mathrm{CaCl}_{2}\left(2.5 \mathrm{mmol} \mathrm{l}^{-1}\right)$ adjusted to $\mathrm{pH} \mathrm{7.4.)}$ The sealed flasks were transported to the laboratory where the spermatozoa were flushed with PBS at $34^{\circ} \mathrm{C}$ from incisions made essentially in the third and fourth segments of the cauda according to the classification of Holtz and Smidt (1976). The sperm suspension, usually from 10-20 boars, was centrifuged ( $2000 \mathrm{~g}$ for $10 \mathrm{~min}$ ), the supernatant solution discarded and the cells aspirated from any denser erythrocytes and resuspended in PBS at $34^{\circ} \mathrm{C}$. This procedure was repeated twice and the spermatozoa were finally prepared as a $10 \%(\mathrm{v} / \mathrm{v})$ suspension in PBS at $34^{\circ} \mathrm{C}$. The concentration of spermatozoa in this suspension was of the order of $10^{7}$ cells $\mathrm{ml}^{-1}$ containing 15-25 $\mathrm{mg}$ protein $\mathrm{ml}^{-1}$.

\section{Incubations with spermatozoa}

Incubations were performed at $34^{\circ} \mathrm{C}$ (boar scrotal temperature) in either $25 \mathrm{ml}$ (short-term) or $50 \mathrm{ml}$ (long-term) open

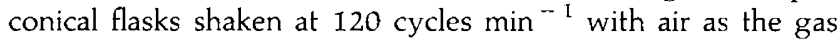
phase. Long-term incubations contained $35 \mathrm{ml}$ (approximately $3-4 \times 10^{8}$ cells) of the $10 \%$ sperm suspensions with no exogenous substrates and, where applicable, $1 \mathrm{ml}$ of the appropriate inhibitor. Samples $(1 \mathrm{ml})$ were removed at zero time and at hourly intervals and added to $3 \mathrm{~mol} \mathrm{HClO}_{4} \mathrm{l}^{-1}$ $(100 \mu \mathrm{I})$. Short-term incubations began at zero time and at hourly intervals by taking $5 \mathrm{ml}$ (approximately $5 \times 10^{7}$ cells) of the long-term incubations, adding this to the appropriate inhibitor $(250 \mu \mathrm{l})$ to a final concentration of $0.5 \mathrm{mmol} \mathrm{l}^{-1}$ and incubating them for $1 \mathrm{~h}$. Samples $(1 \mathrm{ml})$ were removed every $15 \mathrm{~min}$ for the following hour and added to $3 \mathrm{~mol} \mathrm{HClO}_{4} \mathrm{l}^{-1}$ $(100 \mu \mathrm{l})$. Neutralized, deproteinized and desalted incubation solutions (Stevenson and Jones, 1982) were used for assay of glycerol 3-phosphate and lactate (Lang, 1985), ATP (Jaworek and Welsch, 1985a), ADP and AMP (Jaworek and Welsch, 1985b), glycerol (Wieland, 1984), glyceraldehyde (Goedde and Langenbeck, 1984), fructose-1,6-bisphosphate, glyceraldehyde 3-phosphate and dihydroxyacetone phosphate (Michal, 1985) using a Shimadzu UV-I60A spectrophotometer (Shimadzu, Kyoto). Spermatozoa were prepared (Chan and Exton, 1976) and assayed for glycogen content by the procedure of Hugget and Nixon (1957) and protein was estimated (Lowry et al., 1951) on freeze-thawed samples using BSA as the standard.
The adenine nucleotide pool is defined as $[\mathrm{ATP}]+[\mathrm{ADP}]+$ [AMP] and energy charge potentials (ECPs) were calculated according to the method of Atkinson and Walton (1967), where

$$
E C P=\frac{[A T P]+0.5[A D P]}{[A T P]+[A D P]+[A M P]}
$$

\section{Acid hydrolyses}

Samples of L- $\alpha$-glycerophosphorylcholine (GPC) $(5 \mathrm{mmol}$ $1^{-1}, 20 \mathrm{ml}$ ), liberated from its cadmium chloride complex by the supplier's procedure, were incubated with $\mathrm{HCl}(2.5 \mathrm{~mol}$ $\left.1^{-1}, 10 \mathrm{ml}\right)$ at various temperatures $\left(60^{\circ}-75^{\circ} \mathrm{C}\right)$ for $3 \mathrm{~h}$. Aliquots $(750 \mu \mathrm{l})$ were removed every $30 \mathrm{~min}, \mathrm{NaOH}\left(2 \mathrm{~mol} \mathrm{l}^{-1}\right.$, $250 \mathrm{ml}$ ) added, the cooled solutions neutralized and desalted and then assayed for glycerol 3-phosphate. The conditions for the maximum production of glycerol 3-phosphate, and its least hydrolysis, were determined to be $65^{\circ} \mathrm{C}$ for $1.5 \mathrm{~h}$. These conditions were used for the production of glycerol 3-phosphate in hydrolysates as a modification to the procedure of Cooper et al. (1988). Samples (1 ml) of incubation suspensions were centrifuged ( $2000 \mathrm{~g}$ for $5 \mathrm{~min}$ ) and the supernatant solution removed. The pellets were disrupted by sonic oscillation using a Branson B-12 Sonifier (Branson Sonic Power Company, Danbury (T), hydrolysed by the above procedure, the cooled suspensions centrifuged (2000 $\mathrm{g}$ for $5 \mathrm{~min}$ ) and the supernatant solutions neutralized, desalted and assayed for glycerol 3-phosphate.

\section{Saponification of sperm pellets}

Sperm suspensions were incubated for 0 and $5 \mathrm{~h}$ in the absence of exogenous substrates and samples ( $1 \mathrm{ml}$ ) added to pre-weighed centrifuge tubes. After centrifugation (2000 $\mathrm{g}$ for $10 \mathrm{~min}$ ) and removal of the supernatant solution, the wet pellets were weighed and saponified at $70^{\circ} \mathrm{C}$ for $15 \mathrm{~min}$ with $\mathrm{KOH}\left(1 \mathrm{~mol} \mathrm{l}{ }^{-1}, 3 \mathrm{mi}\right)$. Ethanol $(95 \%, 2 \mathrm{ml})$ was added and heating continued for a further $2 \mathrm{~h}$. To the cooled mixture was added $\mathrm{H}_{2} \mathrm{SO}_{4}\left(9 \mathrm{~mol} \mathrm{l} \mathrm{l}^{-1}, 0.5 \mathrm{ml}\right)$ and, after centrifugation $(2000 \mathrm{~g}$ for $5 \mathrm{~min}$ ), the decanted supernatant solutions were neutralized, desalted and assayed for glycerol.

\section{Results}

When incubated at $34^{\circ} \mathrm{C}$ in the absence of exogenous substrates, washed boar spermatozoa maintained a reasonably high energy charge potential (ECP) $(0.5-0.8)$ over $5 \mathrm{~h}$ (Fig. 1). When incubations were performed in the presence of $5 \mathrm{mg} \mathrm{ml}^{-1}$ of penicillin $\mathrm{G}$, ampicillin or tetracycline, the ECP was maintained indicating that it was not due to bacterial contamination. The concentration of lactate decreased from an initial value of $11 \mathrm{nmol} \mathrm{mg} \mathrm{m}^{-1}$ protein over the first hour but remained constant at 2-4 nmol mg ${ }^{-1}$ protein from $I$ to $5 \mathrm{~h}$ (Fig. 2); there was no effect when glyceraldehyde 3-phosphate dehydrogenase and triosephosphate isomerase were inhibited by the addition of CHOP. Incubations performed in the presence and absence of 1,6-dichloro-1,6-dideoxy-D-glucose $\left(10 \mathrm{mmol} \mathrm{l}^{-1}\right)$, 


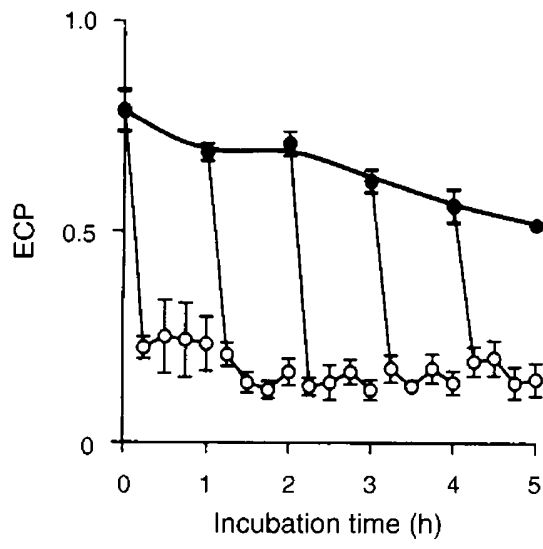

Fig. 1. The energy charge potential (ECP) of boar spermatozoa incubated ( ) without exogenous substrate at $34^{\circ} \mathrm{C}$ for $5 \mathrm{~h}(n=10)$ and the effect of ( 3) 3-chloro-1-hydroxypropanone (CHOP) added each hour $(n=6)$.

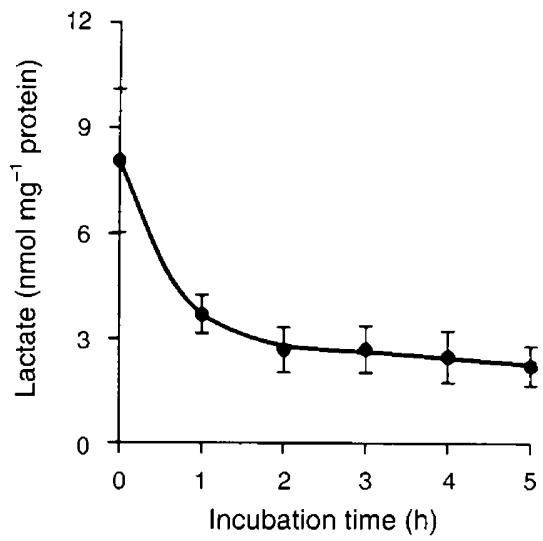

Fig. 2. Concentration of lactate in boar spermatozoa incubated without exogenous substrate at $34^{\circ} \mathrm{C}$ for $5 \mathrm{~h}(\bullet)(n=6)$.

which also inhibits these two enzymes and transiently inhibits aldolase, maintained high ECPs over $\mathrm{Ih}$ in its absence $(0.87 \pm 0.02, n=4)$ and slightly lower in its presence $(0.53 \pm 0.04, n=4)$ and when freshly washed spermatozoa were assayed, glycogen was shown to be absent. The presence of etomoxir $\left(10 \mu \mathrm{mol} \mathrm{l}^{-1}\right)$, an inhibitor of fatty acid transport into mitochondria, had no effect on the ECP over $5 \mathrm{~h}$.

Samples removed from $5 \mathrm{~h}$ incubations at each hour and incubated for a further hour in the presence of CHOP $\left(0.5 \mathrm{mmol} \mathrm{l}^{-1}\right)$ showed that the ECP was unable to be sustained, declining to $0.1-0.25$ (Fig. 1). Detectable concentrations of the glycolytic intermediates fructose-1,6bisphosphate, dihydroxyacetone phosphate and glyceraldehyde 3-phosphate were present over the $5 \mathrm{~h}$ but when $\mathrm{CHOP}$ was added, the concentrations of fructose-1,6-bisphosphate and dihydroxyacetone phosphate were increased (Fig. 3).

Free glycerol 3-phosphate was not detected at any time over the $5 \mathrm{~h}$ incubation and did not accumulate when hourly samples were incubated with CHOP. Samples that were removed at hourly intervals, centrifuged, and the pellet hydrolysed and assayed, did not show a decline in the concentration of glycerol 3-phosphate which remained at 11-12 nmoles $\mathrm{mg}^{-1}$ protein. This was also the case when hourly samples were incubated with CHOP.

Incubations performed in the presence of $(R, S)-\alpha$ bromohydrin phosphate $\left(5 \mathrm{mmol} \mathrm{l}^{-1}\right)$, an inhibitor of glycerol 3-phosphate dehydrogenase, showed a gradual decline in the ECP over $5 \mathrm{~h}$, from 0.9 to 0.5 but the addition of $\mathrm{CHOP}$ each hour decreased this value to $0.1-0.2 \quad(n=6)$. Incubations performed in the presence of $\mathrm{D}, \mathrm{L}$-carnitine chloride $(4 \mathrm{mmol}$ $\mathrm{I}^{-1}$ ) maintained a high ECP but the addition of CHOP each hour decreased this to $0.1-0.2(n=5)$.

When hourly samples of incubations were assayed for glyceraldehyde, none could be detected. However, in the presence of CHOP, 'glyceraldehyde' appeared to accumulate. This was subsequently shown to be an artefact since the assay was not specific for glyceraldehyde; the alcohol dehydrogenase had a much greater affinity for the (S)-3-chlorolactaldehyde produced from CHOP rather than D-glyceraldehyde. No 'glyceraldehyde' could be detected when incubations were performed in the presence of bromopyruvate, an inhibitor of glyceraldehyde 3-phosphate dehydrogenase and 3-phosphoglycerate kinase.

Glycerol was detected during the $5 \mathrm{~h}$ incubation in variable amounts and when hourly samples were incubated in the presence of CHOP, the amount of glycerol increased (Fig. 4). Saponification of sperm pellets showed that the amount of glycerol produced from those incubated for $0 \mathrm{~h}(12.4 \pm 0.6)$ in the absence of CHOP had significantly decreased $(P<0.01)$ in those incubated for $5 \mathrm{~h}\left(9.3 \pm 0.4 \mathrm{nmol} \mathrm{mg}{ }^{-1}\right.$ protein, $\left.n=5\right)$.

\section{Discussion}

After studying an egg yolk buffer medium in an attempt to determine which constituents were responsible for promoting and maintaining the motility of bull spermatozoa for long periods, Lardy and Phillips (194I) reported that "... fractional studies showed that the protein and neutral fat portion of the egg yolk had no beneficial effect in preserving motility of spermatozoa in buffered medium. In fact, the neutral fat rendered the spermatozoa immotile. However, the phospholipid fraction of the egg yolk greatly prolonged the motility of spermatozoa in a buffered medium." Early work on energy production by spermatozoa suggested the presence of an endogenous metabolic substrate thought to be a lipid but later reported to be a plasmalogen (Harrison, 1977), whereas ram spermatozoa incubated in the absence of exogenous substrates showed little or no detectable changes in any phospholipid fraction (Darin-Bennett et al., 1973). Harrison (1977) discounted the use of phospholipids as endogenous substrates and favoured the role of acetyl carnitine as a storage form of acetyl units. Subsequently, Mita and Ueta (1990) showed that sea urchin spermatozoa can maintain their motility in sea water by hydrolysing endogenous phospholipids and producing ATP from the resulting fatty acids and glycerol 3-phosphate.

The prolonged fertilizing life of spermatozoa in bats (Racey, 1979), hares (Martinet and Raynaud, 1975) and mice (Ullman, 1976) indicates that spermatozoa can remain viable for long periods. While this probably occurs by the use of metabolic substrates obtained from the female reproductive tract, the spermatozoa of many species may have the ability to 

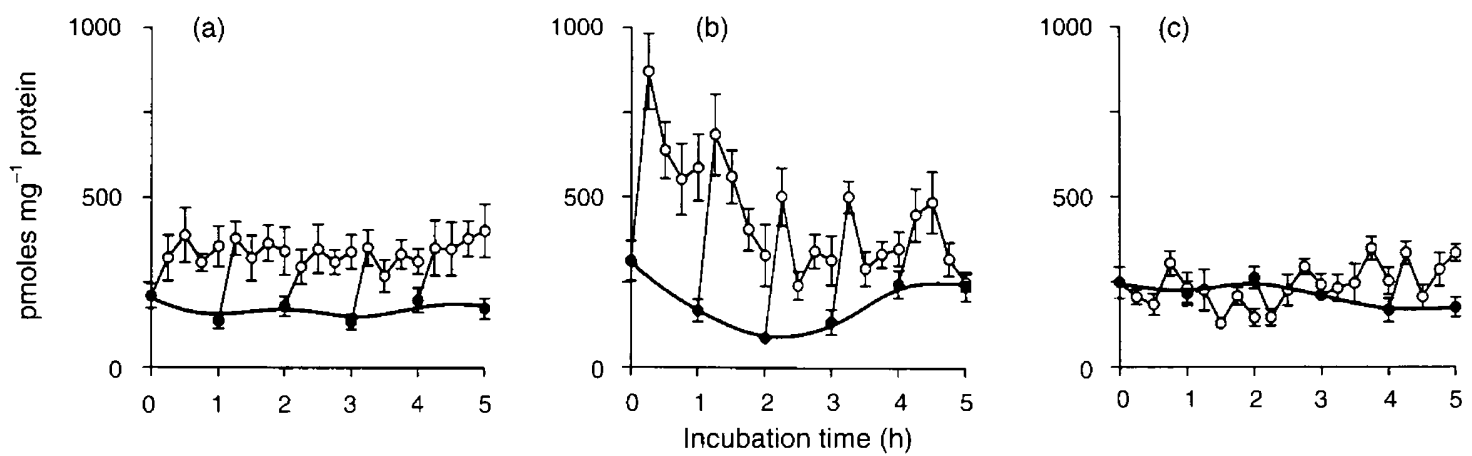

Fig. 3. Concentrations of (a) fructose-1,6-bisphosphate, (b) dihydroxyacetone phosphate and (c) glyceraldehyde 3-phosphate in boar spermatozoa incubated without exogenous substrate at $34^{\circ} \mathrm{C}$ for $5 \mathrm{~h}(\bullet)$ and the effect of $(:)$ 3-chloro-1-hydroxypropanone (CHOP) added each hour $(n=6)$.

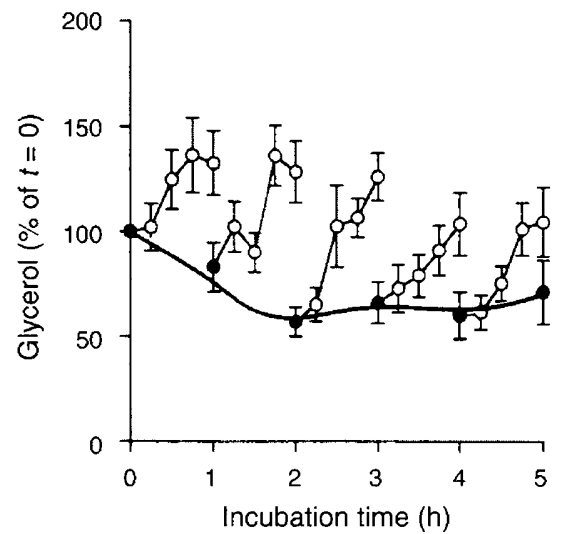

Fig. 4. Concentration of glycerol in boar spermatozoa incubated without exogenous substrate at $34^{\circ} \mathrm{C}$ for $5 \mathrm{~h}(\bullet)$ and the effect of $(c)$ 3-chloro-1-hydroxypropanone (CHOP) added each hour $(n=10)$. Values are compared with the zero time values which were 270 $3100 \mathrm{pmol} \mathrm{mg}^{-1}$ protein.

metabolize an endogenous substrate when no exogenous substrates are available but this substrate (or substrates) may differ from species to species. The present study has shown that washed boar spermatozoa can maintain a high energy charge potential $(E C P)$ for at least $5 \mathrm{~h}$ at $34^{\circ} \mathrm{C}$ when incubated under aerobic conditions in the absence of any exogenous substrate. Boar spermatozoa do not oxidize short- or mediumchain fatty acids (Jones and Chantrill, 1989) and the present study has shown that incubations performed in the presence of the long-chain fatty acid transport inhibitor etomoxir (Wolf et al., 1982) were still able to maintain high ECPs. In the event that the inability of the cells to oxidize fatty acids was due to the washing procedure depleting their carnitine content, incubations were performed in the presence of exogenous carnitine. Addition of CHOP at any period immediately lowered the ECP suggesting that lack of carnitine was not a factor contributing to this inability. Thus the endogenous substrate, which cannot be a ketogenic amine (Jones and Gillan, 1996b), must channel carbon atoms to some point in the glycolytic pathway to produce the lactate which is essential for the mitochondrial production of ATP (Jones, 1997).

As with human spermatozoa (Mann and Rottenberg, 1966), boar spermatozoa contain no detectable quantity of glycogen and incubations performed in the presence of 1,6-dichloro-1,6dideoxy-D-fructose, which inhibits glyceraldehyde 3-phosphate dehydrogenase, triosephosphate isomerase and aldolase (Jones and Morin, 1995), showed only a moderate effect on the ECP over $1 \mathrm{~h}$. Addition of CHOP, an inhibitor of both glyceraldehyde 3-phosphate dehydrogenase and triosephosphate isomerase (Jones and Cooney, 1987), decreased the ECP at any time over a $5 \mathrm{~h}$ incubation. The inhibitory action of CHOP localized the point at which the exogenous carbon atoms were entering the glycolytic pathway to be at or before the formation of the triosephosphates, since there was an accumulation of dihydroxyacetone phosphate and fructose-1,6bisphosphate after its addition. Incubations to which $(R, S)-\alpha-$ bromohydrin phosphate was added maintained a relatively high ECP but not as high as that maintained in its absence. As this compound inhibits the mitochondrial membrane-bound glycerol 3-phosphate dehydrogenase which converts glycerol 3 -phosphate to dihydroxyacetone phosphate (Jones and Gillan, 1996b), it was deduced that a contributing though minor source of a metabolic substrate was producing glycerol 3-phosphate. Glycerol 3-phosphate is rapidly oxidized by boar spermatozoa and its presence in washed cells or semen cannot be detected (Jones and Gillan, 1996a). Possible precursors of glycerol 3-phosphate are membrane phospholipids or glycerylphosphorylcholine, which is present in boar semen to the extent of $1.3 \%$ (Jones, 1978). However, no significant changes could be detected in the concentration of glycerol 3-phosphate when cells were hydrolysed after being incubated for $5 \mathrm{~h}$.

Another possibility was that a metabolic substrate was entering the glycolytic pathway as glyceraldehyde 3phosphate. The metabolism of glycerol by boar spermatozoa has been shown to be as glycerol $\rightarrow$ glyceraldehyde $\rightarrow$ glyceraldehyde 3-phosphate (Jones et al., 1992) so that inhibition of glyceraldehyde 3-phosphate dehydrogenase and triosephosphate isomerase by CHOP may have led to the accumulation of glyceraldehyde 3-phosphate. This was not the case but when glyceraldehyde was assayed, there appeared to be an increase in its concentration. However, further investigation revealed that this was incorrect since the nonspecific assay for glyceraldehyde was estimating (S)-3chlorolactaldehyde, the metabolite of $\mathrm{CHOP}$ which is the actual metabolic inhibitor (Jones et al., 1986). When stage 2 of 
the glycolytic pathway was inhibited by 3-bromopyruvate (Jones et al., 1995), which does not produce an aldehyde, there was no detectable aldehydic material. With either inhibitor there was an increase in the concentration of glycerol and the diglyceride/triglyceride concentration of the cells, as measured by saponification and assay of the glycerol produced, had declined after the $5 \mathrm{~h}$ incubation. Triglycerides have been identified as metabolic energy sources only in one species of sea urchin spermatozoa (Mita and Nakamura, 1993). G. crenularis spermatozoa contain lipid globules within their mid-pieces and, when incubated in sea water with no substrate for $1 \mathrm{~h}$, these globules were reduced in size, some fatty acids were oxidized but there was also an increase in the concentration of free fatty acids. Boar spermatozoa are known to possess a pool of diglycerides that are actively involved in phospholipid synthesis (Vazquez and Roldan, 1997) and it may be that this is the source of the glycerol.

We conclude that there are at least two endogenous materials that washed boar spermatozoa can mobilize when they are incubated in the absence of any exogenous substrate. One material is degraded to glycerol 3-phosphate, although this appears to be a minor contributor to the production of ATP. Inhibition of the oxidation of glycerol 3-phosphate by the presence of $(R, S)-\alpha$-bromohydrin phosphate lowered the $\mathrm{ECP}$ to a slight degree, whereas the further addition of $\mathrm{CHOP}$ immediately caused the ECP to decline rapidly. The major contributor is mobilized to produce glycerol which provides the carbon atoms for the production of lactate. If this glycerolproducing material is di- or tri-glycerides, as data from saponification studies suggest, then this raises an interesting question. Why do boar spermatozoa break down these substrates and only oxidize the glycerol? Further studies are in progress to identify these endogenous materials and when this is done, the question may be answered.

This work was supported by the New South Wales Government Employees Medical Research Fund. The authors thank the employees of the F. C. Nichol abattoir at Woy Woy, NSW for assistance in the collection of boar tissue.

\section{References}

Atkinson DE and Walton GM (1967) Adenosine triphosphate conservation in metabolic regulation Journal of Biological Chemistry 242 3239-3241

Bohnensack R and Halangk W (1986) Control of respiration and of motility in ejaculated bull spermatozoa Biochimica et Biophysica Acta 850 72-79

Chan TM and Exton JH (1976) A rapid method for the determination of glycogen content and radioactivity in small quantities of tissue or isolated hepatocytes Analytical Biochemistry 71 96-105

Cooper TG, Yeung C-H, Nashan D and Nieschlag E (1988) Epididymal markers in human infertility International Journal of Andrology 9 91-101

Darin-Bennett A, Poulos A and White IG (1973) A re-examination of the role of phospholipids as energy substrates during incubation of ram spermatozoa journal of Reproduction and Fertility 34 543-546

Ford WCL and Rees JM (1990) The bioenergetics of mammalian sperm motility. In Controls of Sperm Motility: Biological and Clinical Aspects Ed. C Gagnon pp 175-202. CRC Press, Boca Raton, FL

Goedde HW and Langenbeck U (1984) Glycolaldehyde. In Methods of Enzymatic Analysis (3rd Edn) Ed. HU Bergmeyer pp 614-618. Verlag Chemie, Weinheim

Harrison RAP (1977) The metabolism of mammalian spermatozoa. In Frontiers in Reproduction and Fertility Control. Part 2 Eds RO Greep and MA Koblinsky pp 307-401. MIT Press, Cambridge MA
Hofmann R, Lehmer A, Gurster E and Harturg R (1992) Adenosine triphosphate and adenosine diphosphate in human semen: correlation with sperm count and motility Urology International $\mathbf{4 8} 391-394$

Holtz W and Smidt D (1976) The fertilising capacity of epididymal spermatozoa in the pig Journal of Reproduction and Fertility 46 227-229

Hoskins DD and Patterson DL (1968) Metabolism of rhesus monkey spermatozoa Journal of Reproduction and Fertility 16 183-195

Hugget AG and Nixon DA (1957) Use of glucose oxidase peroxidase and o-dianisidine in determination of blood and urinary glucose Lancet $\mathbf{2 4}$ $368-370$

Jaworek D and Welsch J (1985a) Adenosine 5'-triphosphate:UV method with phosphoglycerate kinase. In Methods of Enzymatic Analysis (3rd Edn) Ed. HU Bergmeyer pp 340-345. Verlag Chemie, Weinheim

Jaworek D and Welsch J (1985b) Adenosine $5^{\prime}$-diphosphate and adenosine $5^{\prime}$-monophosphate: UV method. In Methods of Enzymatic Analysis (3rd Edn). Ed. HU Bergmeyer pp 365-369. Verlag Chemie, Weinheim

Jones AR (1997) Metabolism of lactate by mature boar spermatozoa Reproduction, Fertility and Development 9 227-232

Jones AR and Chantrill LA (1989) Oxidative metabolic activity of boar spermatozoa: a system for assessing anti-glycolytic activity of potential inhibitors in vitro. Reproduction. Fertility and Development $1357-367$

Jones AR and Cooney SJ (1987) Inhibition of triosephosphate isomerase in boar spermatozoa by (S)-3-chlorolactaldehyde Biochemical and Biophysical Research Communications 145 1054-1058

Jones AR and Gillan L (1996a) Glycerol 3-phosphate dehydrogenase of boar spermatozoa: inhibition by $\alpha$-bromohydrin phosphate Journal of Reproduction and Fertility 108 95-100

Jones AR and Gillan L (1996b) Metabolism of glycerol 3-phosphate by mature boar spermatozoa Journal of Reproduction and Fertility $106321-$ 327

Jones AR and Morin C (1995) Inhibition of glycolysis in boar spermatozoa by 1,6-dichloro-1,6-dideoxy-0-fructose Biochimica et Biophysica Acta $\mathbf{1 2 4 4}$ 14I-146

Jones AR and Porter LM (1995) Inhibition of glycolysis in boar spermatozoa by $\alpha$-chlorohydrin phosphate appears to be mediated by phosphatase activity Reproduction, Fertility and Development 7 1089-1094

Jones AR, Bubb WA, Murdoch SR and Stevenson D (1986) Inhibition of fructolytic enzymes in boar spermatozoa by (S)- $\alpha$-chlorohydrin and 1-chloro-3-hydroxypropanone Australian joumal of Biological Sciences 39 395-406

Jones AR, Chantrill LA and Cokinakis A (1992) Metabolism of glycerol by mature boar spermatozoa Journal of Reproduction and Fertility 94 129134

Jones AR, Gillan L and Milmlow D (1995) The anti-glycolytic activity of 3-bromopyruvate on mature boar spermatozoa in vitro. Contraception $\mathbf{5 2}$ $317-320$

Jones R (1978) Comparative biochemistry of mammalian epididymal plasma Comparative Biochemistry and Physiology 61B 365-370

Lang G (1985) L + (-)-Glycerol 3-phosphate. In Methods of Enzymatic Analysis (3rd Edn) Vol. Vl pp 525-530 Ed. HU Bergmeyer. Verlag Chemie, Weinheim

Lardy HA and Phillips PH (1941) Phospholipids as a source of energy for motility of bull spermatozoa American Joumal of Physiology $134542-$ 548

Lowry OH, Roseborough NJ, Farr AL and Randall RJ (195I) Protein measurement with the Folin phenol reagent Journal of Biological Chemistry 193 265-275

Mann T and Lutwak-Mann C (1981) Male Reproductive Function and Semen p 200. Springer-Verlag, Berlin

Mann T and Rottenberg DA (1966) The carbohydrate of human semen Journal of Endocrinology 34 257-264

Martinet L and Raynaud F (1975) Prolonged spermatozoa survival in the female hare uterus: explanation of superfetation. In The Biology of Spermatozoa: Transport, Survival and Fertilizing Capacity pp 134-44 Eds ESE Hafez and CG Thibault. Karger,Basel

Michal G (1985) D-Fructose-1,6-bisphosphate, dihydroxyacetone phosphate and D-glyceraldehyde-3-phosphate. In Methods of Enzymatic Analysis (3rd Edn) Ed. HU Bergmeyer pp 342-350. Verlag Chemie, Weinheim

Mita M and Nakamura M (1993) Lipid globules at the midpieces of Glyptocidaris crenularis spermatozoa and their relation to energy metabolism Molecular Reproduction and Development 34 158-163 
Mita M and Ueta N (1990) Phosphatidylcholine metabolism for energy production in sea urchin spermatozoa Biochimica et Biophysica Acta 1047 175-179

Mita M, Harumi T, Suzuki N and Ueta N (1991) Localisation and characterisation of phosphatidylcholine in sea urchin spermatozoa Journal of Biochemistry 109 238-242

Racey PA (1979) The prolonged storage and survival of spermatozoa in Chiroptera. Journal of Reproduction and Fertility 56 391-402

Stevenson D and Jones $\mathrm{AR}$ (1982) Inhibition of fructolysis in boar spermatozoa by the male antifertility agent (S)- $\alpha$-chlorohydrin Australian Journal of Biological Sciences 35 595-605

Tash JS and Mann T (1973) Adenosine $3^{\prime}: 5^{\prime}$-cyclic monophosphate in relation to motility and senescence of spermatozoa Proceedings of the Royal Society of London Series B $\mathbf{1 8 4} 109-114$
Uliman SL (1976) Anomalous litters in hybrid mice and the retention of spermatozoa in the female tract joumal of Reproduction and Fertility 47 $13-18$

Vazquez JM and Roldan ERS (1997) Phospholipid metabolism in boar spermatozoa and role of diacylglycerol species in the de novo formation of phosphatidylcholine Molecular Reproduction and Development 47 105-112

Wieland OH (1984) Glycerol UV-method. In Methods of Enzymatic Analysis (3rd Edn) Ed. HU Bergmeyer pp 504-510. Verlag Chemie, Weinheim

Williams P, Payne GB, Sullivan G and Van Ess PR (1960) Chemistry of glycidaldehyde Journal of the American Chemical Society 82 4883-4888

Wolf HPO, Eistetter K and Ludwig G (1982) Phenylalkyloxirane carboxylic acids, a new class of hypoglycemic substances. Hypoglycemic and hypoketonemic effect of sodium 2-[5-\{4-chlorophenyl)-pentyl]-oxirane-2 carboxylate (B 807-27) in fasted animals Diabetologia 22 456-463 